Article

\title{
Education and Training in Applied Remote Sensing in Africa: The ARCSSTE-E Experience
}

\author{
Ganiyu Agbaje, Omowumi Alabi and Etim Offiong * \\ African Regional Center for Space Science and Technology Education in English (ARCSSTE-E), \\ PMB 019, Ile-Ife 220005, Nigeria \\ * Correspondence: etim.offiong@arcsstee.org.ng; Tel.: +234-803-588-3475
}

Received: 15 May 2019; Accepted: 29 July 2019; Published: 2 August 2019

\begin{abstract}
In Africa, there is growing knowledge regarding the use of data obtained by remote sensing and analysed while using Geographic Information Systems for solving myriad problems. The awareness has largely arisen through the efforts of the Programme on Space Applications (PSA) of the United Nations Office for Outer Space Affairs (UNOOSA), and the subsequent UN resolutions for the establishment of Regional Centres for Space Science and Technology Education, to train scientists and researchers in different thematic areas of space, including Remote Sensing/Geographic Information Systems (RS/GIS). The African Regional Centre for Space Science and Technology Education in English (ARCSSTE-E) is one of these regional centres. The Centre has successfully trained 474 professionals from 18 countries since its inception in 1998; about $14 \%$ of these trainees have been female. This paper highlights the training programmes of ARCSSTE-E from its inception, and discusses the potential areas of improvement with a focus on the RS/GIS area. In 2019, a survey was conducted on alumni of the Postgraduate Diploma (PGD) programme of ARCSSTE-E. Based on the analysis of their responses and the progression of the PGD programme to a new Masters programme in RS/GIS at the university, there is clear evidence regarding the impact of the UNOOSA-assisted capacity building programme on the work and career of alumni, which has already produced an appreciable number of trained personnel in developing countries in Africa.
\end{abstract}

Keywords: remote sensing; Geographic Information Systems; capacity building; education; training

\section{Introduction}

The United Nations General Assembly charged the Programme on Space Applications (PSA), of the United Nations Office for Outer Space Affairs (UNOOSA), with the "development of a fellowship programme for in-depth training of space technologists and applications specialists, with the help of Member States and relevant international organisations, and the establishment and regular up-dating of lists containing available fellowships in all States and relevant international organizations" following the outcome of the Second United Nations Conference on the Exploration and Peaceful Uses of Outer Space in 1982 (UNISPACE II) [1]. The focus was to build indigenous capacities for the development and utilisation of Space Science and Technology, particularly at the local level. To fulfill this objective, the UNOOSA, with the active support of its specialised agencies and other international organisations, was mandated to lead an international effort to establish Regional Centres for Space Science and Technology Education in existing national/regional educational institutions in developing countries [2]. UNOOSA then established the first regional centre in India in 1995. In 1998, two other Regional Centres were established in Morocco and Nigeria, for French-speaking and English-speaking countries in Africa, respectively. With the success of UNSPACE III, the UN General Assembly (UNGA) decided to strengthen the activities of the UNOOSA [3] with the establishment of the Regional Center in Mexico, with a campus in Brazil, in 2003. Two Regional Centres were later established in Jordan and China 
in 2012 and 2014, respectively. Figure 1 shows the locations of the centres, which have become a successful case study regarding cross border education [4]. The figure also shows, countries in Africa that are being served by ARCSSTE-E in red.

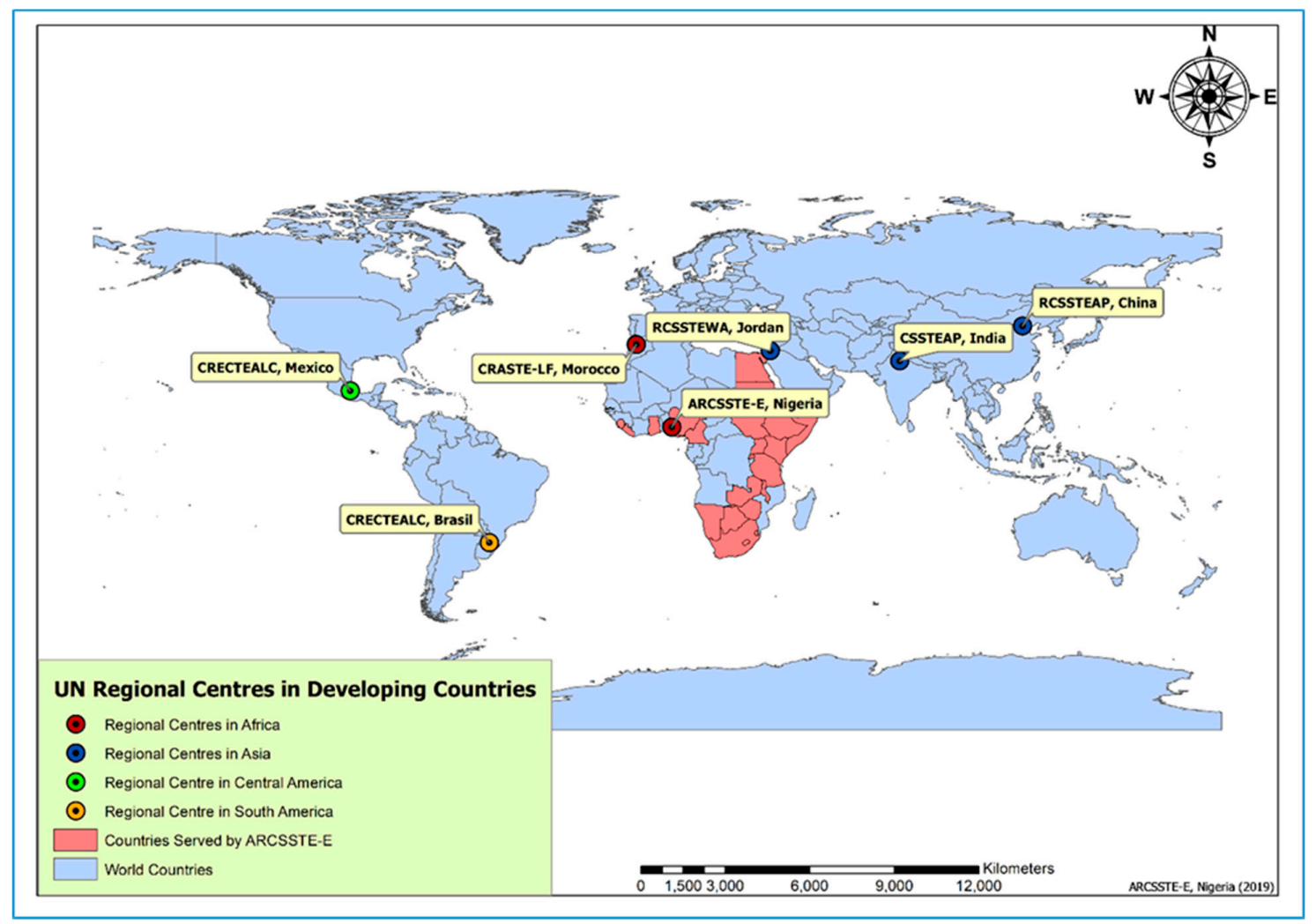

Figure 1. Map showing the locations of the UN-affiliated Regional Centres for Space Science and Technology Education. Regions that are highlighted in red represent the countries covered by ARCSSTE-E.

The mandate of the Regional Centres is to educate and train scientists and researchers in thematic areas of space applications. Curricula for four thematic areas were developed at the conception of the initiative, namely: Remote Sensing/Geographic Information Systems; Satellite Communications; Satellite Meteorology; and, Basic Space Science/Atmospheric Physics [5]. These curricula were revised in 2001 to include newer developments in each of the thematic areas [6]. In 2013, a curriculum for Global Navigation Satellite Systems (GNSS) was developed, and the course was introduced into the programme. A year later, the curriculum for Space Law was introduced. Efforts are currently underway for the development of a curriculum for Satellite Engineering.

The following sections discuss the education and training activities of ARCSSTE-E and its successes and challenges, as well as efforts by ARCSSTE-E to improve on its programmes. We highlight how past participants have benefitted from the programmes and applied the knowledge and skills that were gained in their professions/careers. The input of past participants was obtained through a survey that was conducted in 2019. A similar survey was conducted on the cohort of 2019 during a foundational course on remote sensing to assess the effectiveness of the training methodology employed, to enhance learning. The best practices that we highlight and recommendations for improvement of the best practices at the end of the paper could be useful for international educational institutions. 


\section{Programmes of the African Regional Centre for Space Science and Technology Education in English (ARCSSTE-E)}

Nigeria was selected to host the Regional Centre for the English-speaking African countries. On 24th November 1998, a tripartite agreement was signed among the United Nations Office for Outer Space Affairs (UNOOSA), the Federal Ministry of Science and Technology (on behalf of the Nigerian government), and the Obafemi Awolowo University (OAU), Ile-Ife, Nigeria (as the host). OAU was chosen due to the availability of university faculty who have expertise in the different courses, as well as the availability of relevant facilities and resources. The earlier citing of the Regional Centre for Training in Aerospace Surveys (now called the African Regional Institute for Geospatial Information Science and Technology) also contributed to making OAU a suitable choice. The university additionally granted a large expanse of land, where the Centre currently operates from. Students have access to the medical and library facilities of the university. The university has also benefitted from the presence of ARCSSTE-E on its campus. For example, it commenced a Masters and PhD programme in RS/GIS after relevant faculty interaction with ARCSSTE-E. Presently, it is developing a programme on Aeronautical Engineering with a contribution from ARCSSTE-E, especially in the area of data and staff.

The Centre annually awards a full scholarship to international participants to facilitate the participation of foreign students in the postgraduate programmes of ARCSSTE-E. This scholarship is sponsored by UNOOSA and the Nigerian government. UNOOSA provides travel tickets for foreign participants on the Postgraduate Diploma (PGD) programme, while the Nigerian government makes a provision for living allowances, which includes accommodation and monthly stipends. This arrangement enables participants to travel to Nigeria and live there for the nine months of study. The Nigerian government also funds the salaries of staff and the operational cost of running the Centre. Publicity for the programme has largely been through alumni and word-of-mouth due to the quality of the programme. Self-funded participants are gradually increasing.

\subsection{The Post Graduate Diploma (PGD) Programme}

The PGD programme at ARCSSTE-E is divided into three phases: common modules, core modules, and a project. The objective of the common modules is to encourage participants to have foundational knowledge regarding all of the course options, as well as other relevant topics. The modules covered in this phase are Space Biology; Fundamentals of Remote Sensing and GIS; Introduction to Space Law; and, Research Methodology. After this phase, the participants are divided into their chosen course options, where they focus on their core modules in line with the UN curriculum. In the third phase of the project, the students undertake individual projects. Dividing the programme into phases/modules has been found to be effective, as participants undertake tests and an examination after each module, thereby keeping them mentally engaged. Participants are given short breaks after each phase. Additionally, participants who are interested in a particular module can join the programme when the module is about to commence, and obtain a Certificate of Participation for that module. Participants who complete the entire course obtain a Diploma certificate that is endorsed by ARCSSTE-E and UNOOSA.

Since 2001, ARCSSTE-E has annually run the Remote Sensing and Satellite Communications course options. Interest in Satellite Meteorology and Basic Space Science has been very low. GNSS as a core option has been run three times (in 2014, 2018, and 2019), while Space Law is run as a general module for all of the participants. The Centre runs the courses using curricula that were developed by experts assembled by UNOOSA, and that are meant to be revised every $3-5$ years. UNOOSA has made the curricula available online [7], thereby making it accessible to other interested institutions. While a course on Satellite Engineering has not formally started, ARCSSTE-E established a Department of Space Engineering, partly to develop in-house capacity in the design and development of small satellites, subsystems, and components. The department also participates in mission design contests and launch opportunities from UNOOSA and international partners. A laboratory for microgravity studies was also established to promote education and research in microgravity in primary and secondary schools $[8,9]$. 
Thus far, a total of 474 professionals from 18 African countries have participated in ARCSSTE-E's PGD programme to date. Figure 2 shows the distribution of participants from 2001 to 2018, while Figure 3 shows the countries that have participated in the programme and the number of beneficiaries from each country. There is a high number of participants from Nigeria, because self-funded students from Nigeria do not need to pay for flight fares (hence, their cost of participation is reduced to payment for tuition and accommodation only); self-funded students from outside Nigeria would need to cater for additional flight fares and other contingent expenses. Of the 55 participants in the current academic year (2019), six are non-Nigerians and each received a full sponsorship from the Nigerian government, while the remaining 49 , who are Nigerians, are all privately funded. This is a general trend in regional institutions in Africa, where the host countries bear the bulk, and in some cases, all of the financial burden.

Figure 4 shows the distribution of participants according to course options. A large percentage of participants choose the Remote Sensing/GIS option due to its wide application in areas, such as land management, natural resource management, disaster management, and environmental management. A total of 291 candidates have received training in Remote Sensing/GIS through the PGD programme. About $20 \%$ of these are females. Successful participants have gone on to get jobs in diverse sectors, such as the public sector, private sector, academia, civil society, military, and international organisations. Some of the participants have successfully started their own businesses. In a previous "post-training" survey that was conducted in 2012 by ARCSSTE-E, it was observed that a large percentage of alumni reside in Africa, while a few that are abroad are either working with international organisations or undertaking further studies [10]. They all attested to the positive impact of the PGD programme on their careers.

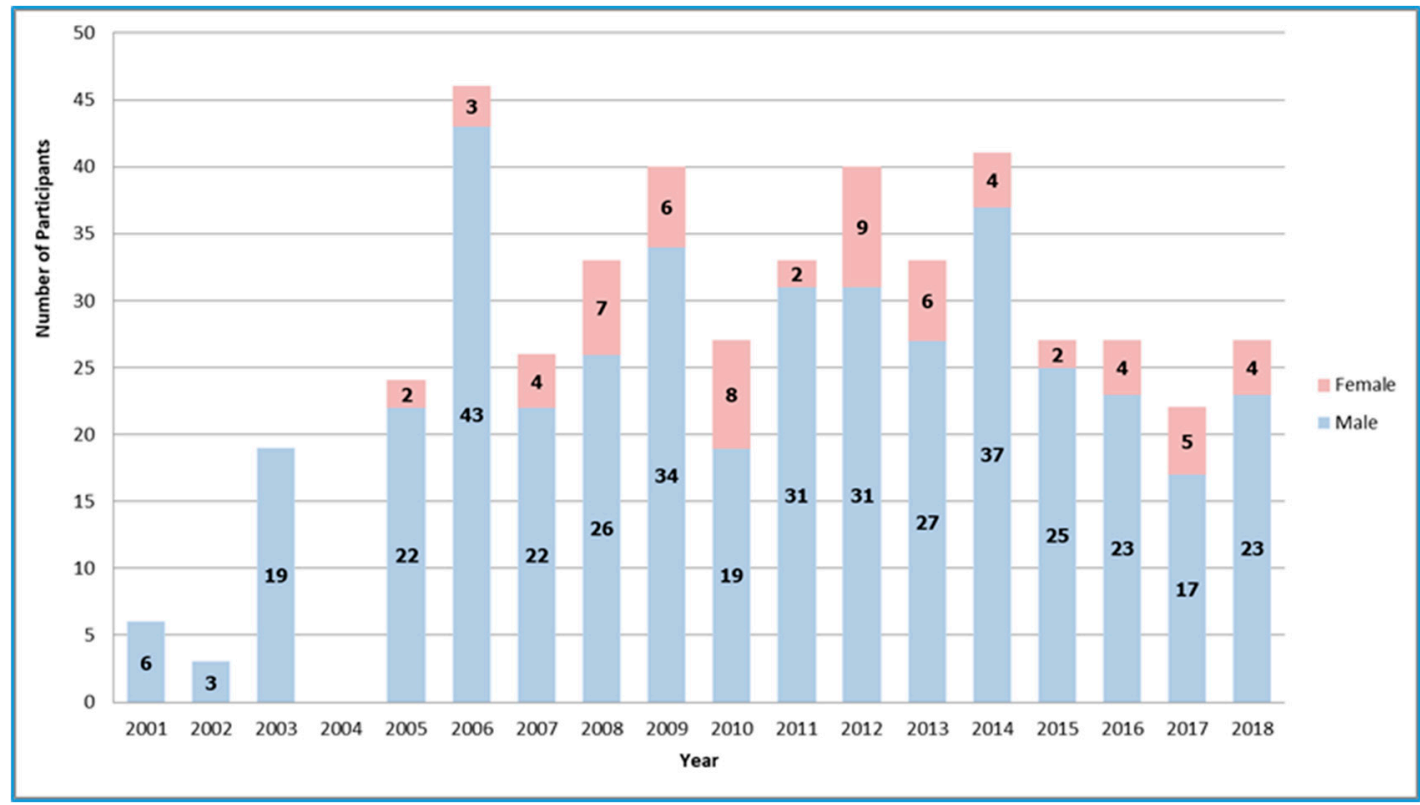

Figure 2. Annual distribution of students in the PGD programme of African Regional Centre for Space Science and Technology Education in English (ARCSSTE-E) from 2001 to 2018. Each bar shows the number of females relative to males. 


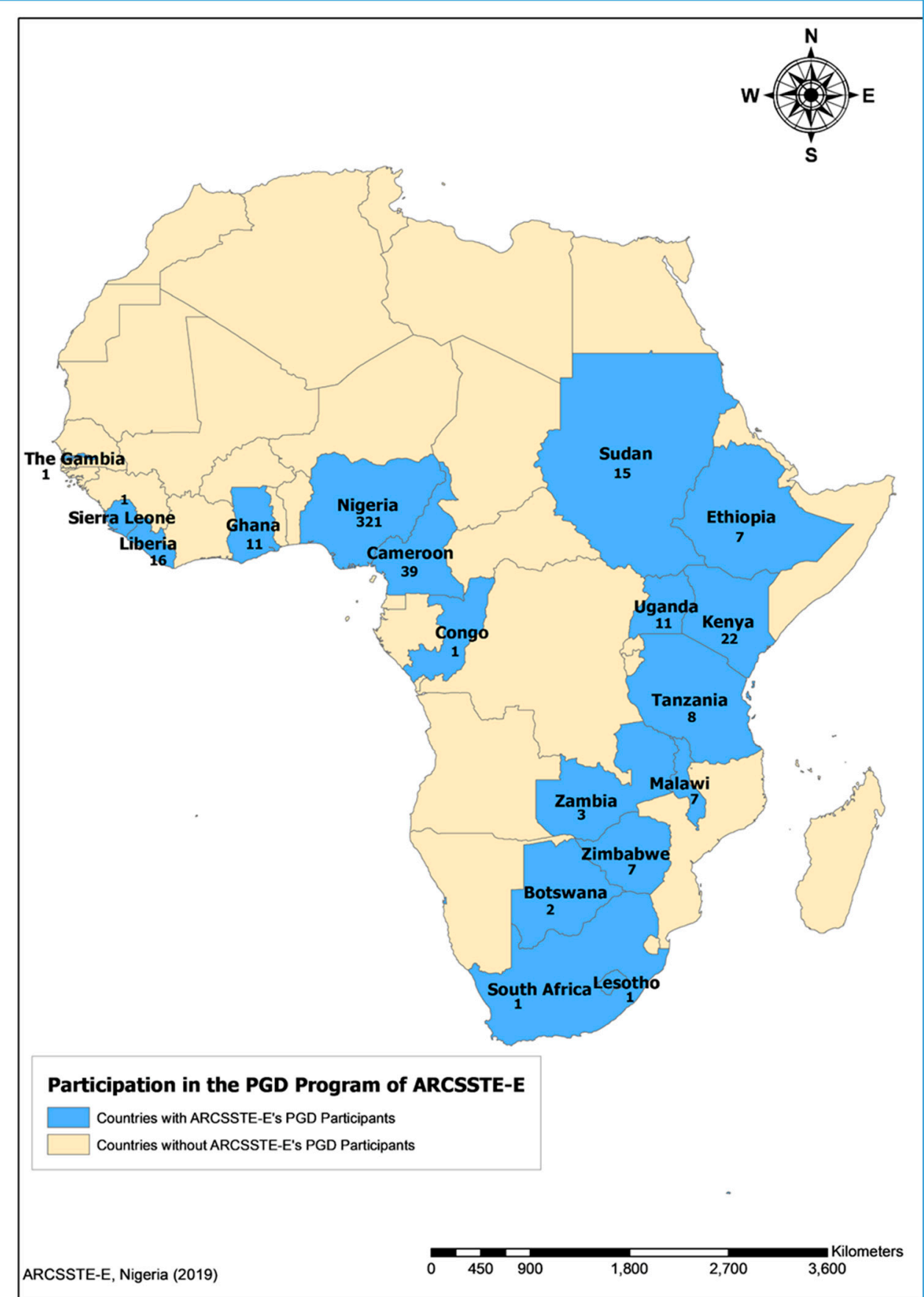

Figure 3. Distribution of participants of the Postgraduate Diploma (PGD) programme of ARCSSTE-E according to countries from 2001 to 2018. 


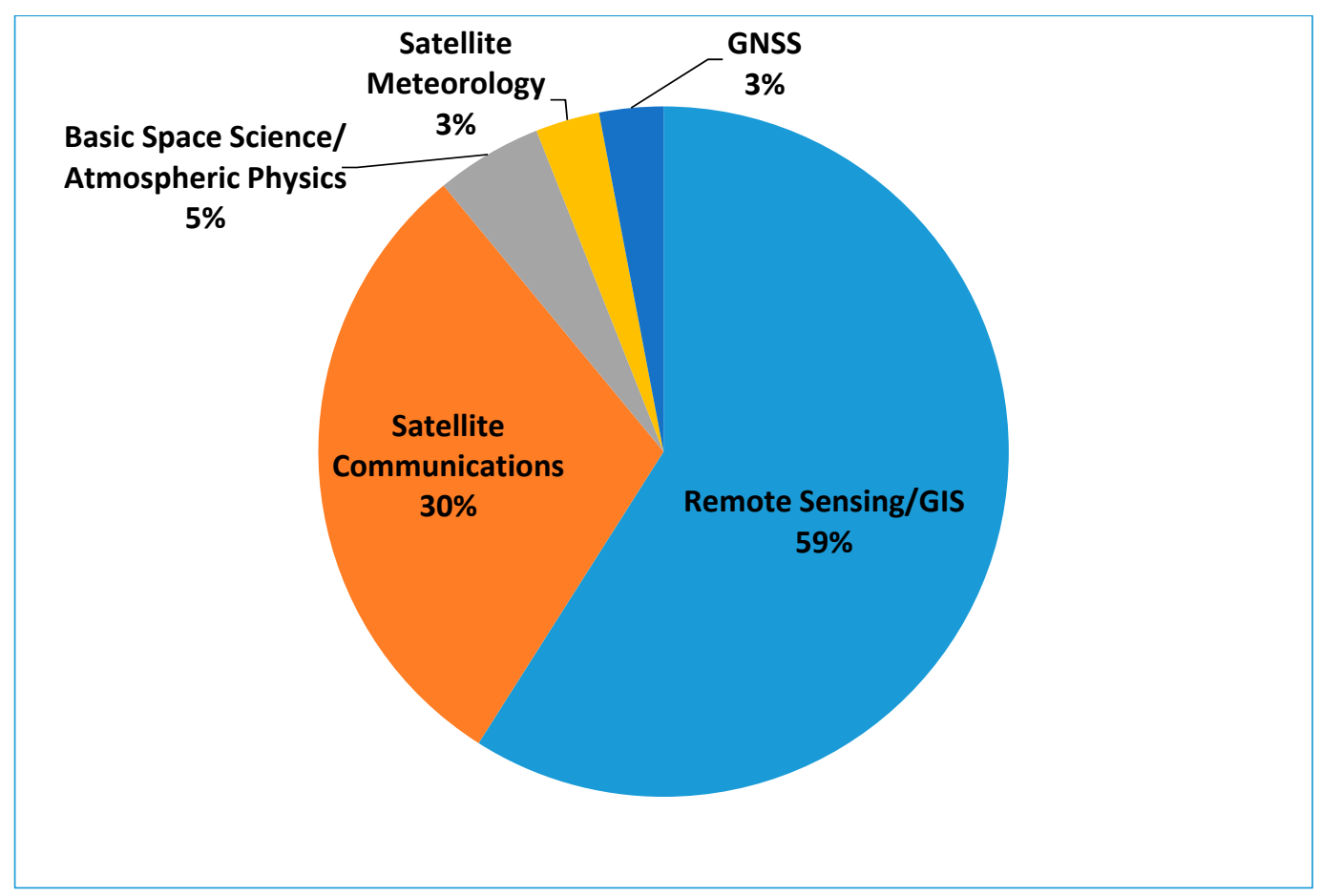

Figure 4. Distribution of participants of the PGD programme of ARCSSTE-E according to course options from 2001 to 2018.

A strong component of the course content is to meet regional and global interests and development agendas. At the regional level, ARCSSTE-E is contributing to the 'Agenda 2063' programme [11] of the African Union, particularly Goal 2 (well-educated citizens and skills revolution underpinned by science, technology, and innovation), Goal 6 (blue/ocean economy for accelerated economic growth), and Goal 7 (environmentally sustainable and climate resilient economies and communities) [12]. Further, a key component of the African Space Policy [13] and the African Space Strategy [14] is capacity development in earth observation, as well as other thematic areas. ARCSSTE-E has also positioned itself to meet this need. At the global level, ARCSSTE-E is contributing to meeting the Sustainable Development Goals (SDGs) of the United Nations through indigenous capacity development. Specific SDG-related courses that are offered in the PGD programme include Sustainable Development and Carrying Capacity; Urban Planning; and, Cost-Benefit Analysis. Furthermore, ARCSSTE-E is contributing to the Sendai Framework for Disaster Risk Reduction 2015-2030, through its course on 'Natural Disasters and Management'.

\subsection{Other Programmes}

Master's Programme: In 2012, ARCSSTE-E signed a Memorandum of Understanding with the Federal University of Technology, Akure (FUTA), Nigeria, for the development and operation of a joint Master's programme in Space Science and Technology Applications. The average length of the programme is 18 months and two course options are currently offered, namely the Remote Sensing/GIS and Satellite Communication (Satcom) options. The first set of students was admitted in 2013. Fifteen of the alumni of the Master's programme had previously participated in the PGD programme of ARCSSTE-E.

Continuous Development Programme: ARCSSTE-E organises short courses and other continuous development programmes in remote sensing. The courses provide the opportunity for participants to update their skills and knowledge. In a recent survey that was conducted in 2019 (see description in Section 3), alumni indicated that they would like to acquire skills in analysing radar and lidar images, 
writing of scripts and small programmes, and in terrain analysis. These would be organised under the continuous development programme.

Research Programme: In addition to education and training, ARCSSTE-E engages in research, innovation, and grantsmanship. For example, in 2017, ARCSSTE-E led a consortium of institutions in West Africa to bid for the implementation of the Multi-Scale Flood Monitoring and Assessment in West Africa project, under the Global Monitoring of the Environment and Security (GMES) and Africa initiative [15]. The consortium won a contract to develop solutions to mitigate flooding problems in West Africa while using satellite data from the constellation of Sentinel satellites [16]. The GMES \& Africa Support Programme initiative is a culmination of a long-standing cooperation between Africa and Europe in space science and technology, which is one of the key priorities of the joint European Union (EU)-Africa Union (AU) strategy. Additionally, in 2017, ARCSSTE-E initiated research in the northern region of Nigeria, titled 'Desertification Monitoring System over the Sahelian Region of Nigeria'. The rationale for the research was that a system of information is vital for an accurate assessment of the processes that lead to desertification and droughts. The objectives of the research include continuously measuring parameters (pressure, temperature, humidity, wind velocity, and rain rate); analysing data obtained and ascertaining whether desertification is occurring or not; modelling the possible rate, volume and direction of future encroachments; and, generating a hazard map for affected areas.

\section{Feedback from Participants}

ARCSSTE-E uses two independent surveys to collect feedback from participants. The first survey, which is an "in-training survey", was introduced to the PGD programme of ARCSSTE-E in 2009. This anonymous survey is conducted at the end of each of the common and core modules of the PGD programme to appraise the learning experience of the participants. The second evaluation by the participants, which is a "post-training survey" for alumni, was introduced in 2012 [10]. The survey for the alumni is designed to assess the impact of the training program of ARCSSTE-E on the professional life of each participant.

This section deliberates on the outcome of a post-training survey that was conducted on the alumni of the PGD programme of ARCSSTE-E in 2019. For this survey, questionnaires were distributed to about 200 alumni via their emails. Thirty-eight alumni, including 27 males and 11 females, responded to the on-line "post-training survey". These respondents were drawn from eight countries: Botswana, Cameroon, Ethiopia, Ghana, Kenya, Liberia, Nigeria, and Zimbabwe. Figure 5 shows the geographic distribution of the respondents. The survey participants who were young professionals, with an average age between 25 and 44 years, included military personnel, health workers, meteorologists, engineers, and scientific officers from Space Agencies. Figure 6 shows the distribution of the respondents according to the sectors in which they work.

The "post-training survey" was designed to assess the impact of the PGD programme on the work and career of the alumni, and to discover how the program enhanced the application of remote sensing data in their place of work. A total of $85 \%$ of the survey participants acknowledged a positive impact of the training program at ARCSSTE-E on their professional life. When the alumni were asked to specify the environmental areas that they have applied the knowledge and skills gained from the training in remote sensing at ARCSSTE-E, $41 \%$ of the respondents indicated that they apply remote sensing in land management. Other identified areas of remote sensing in their work applications included disaster management (39\%), water resource management (37\%), ecology $(21 \%)$, and air pollution $(11 \%)$. Figure 7 depicts the environmental areas in which the alumni specified use of the knowledge and skills that were gained from their training in remote sensing at ARCSSTE-E. 


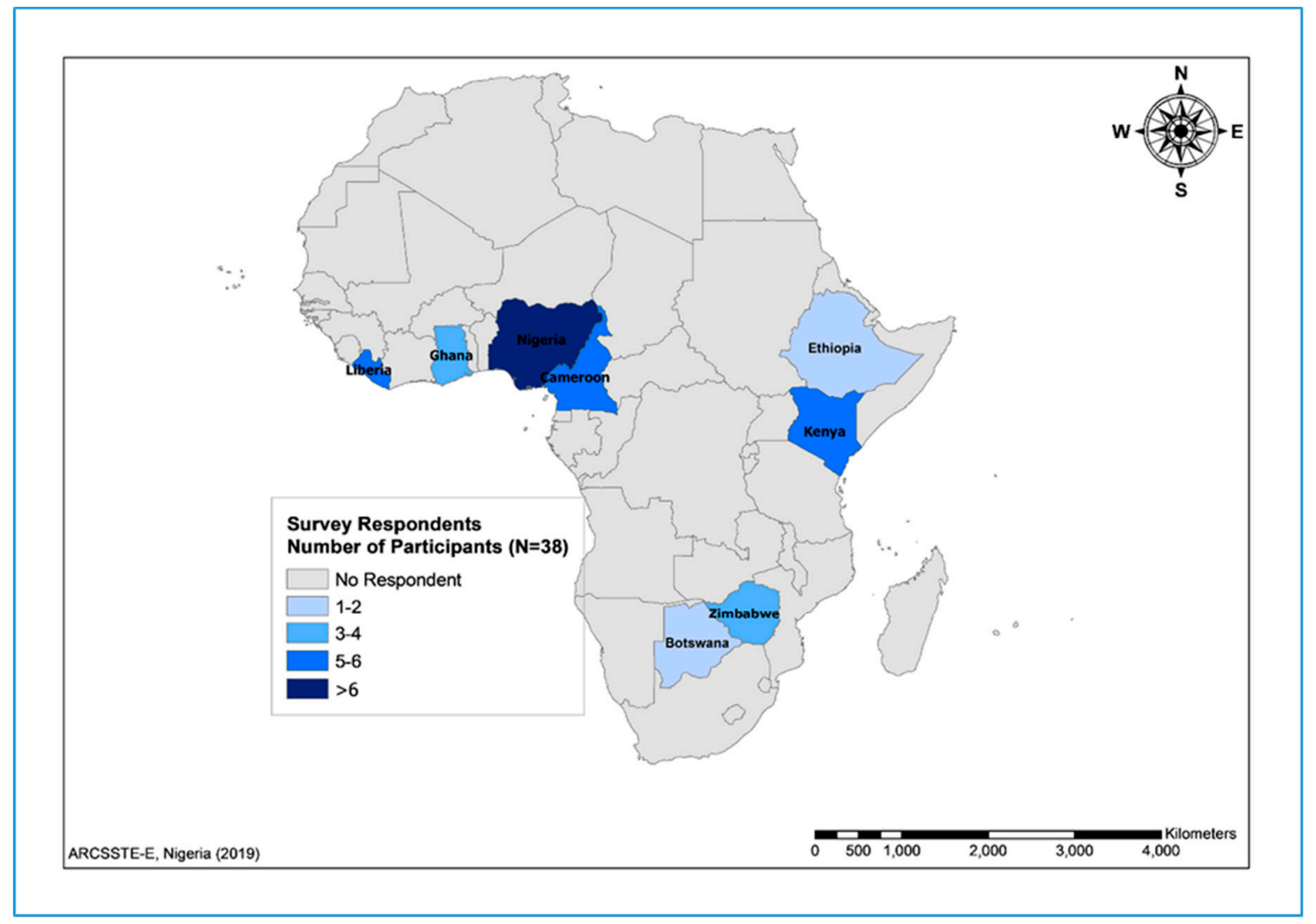

Figure 5. Number of ARCSSTE-E survey respondents per country. There were 38 participants from eight African countries.

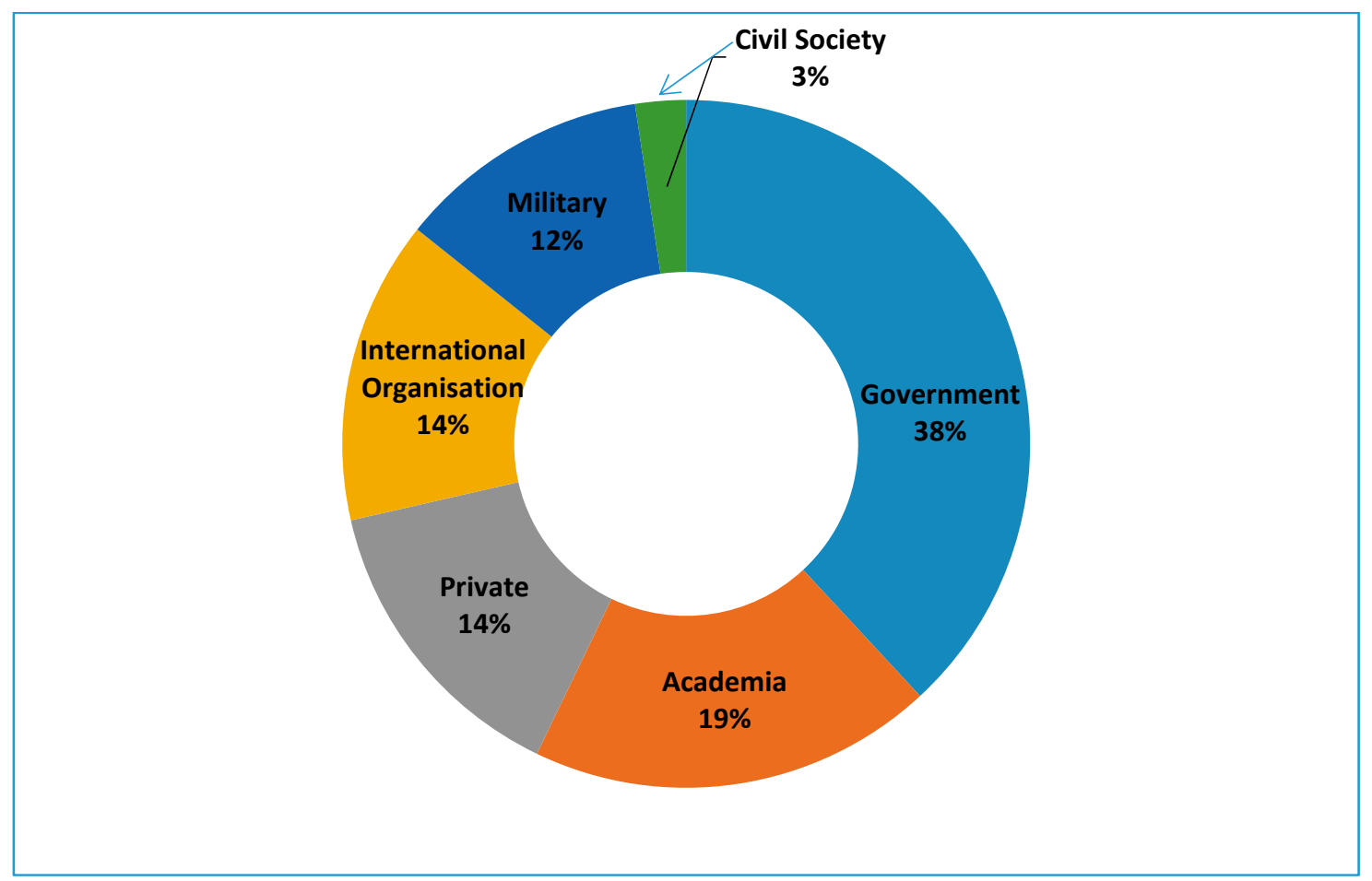

Figure 6. The distribution of the ARCSSTE-E's survey respondents according to self-identified work sectors $(\mathrm{N}=38)$. 


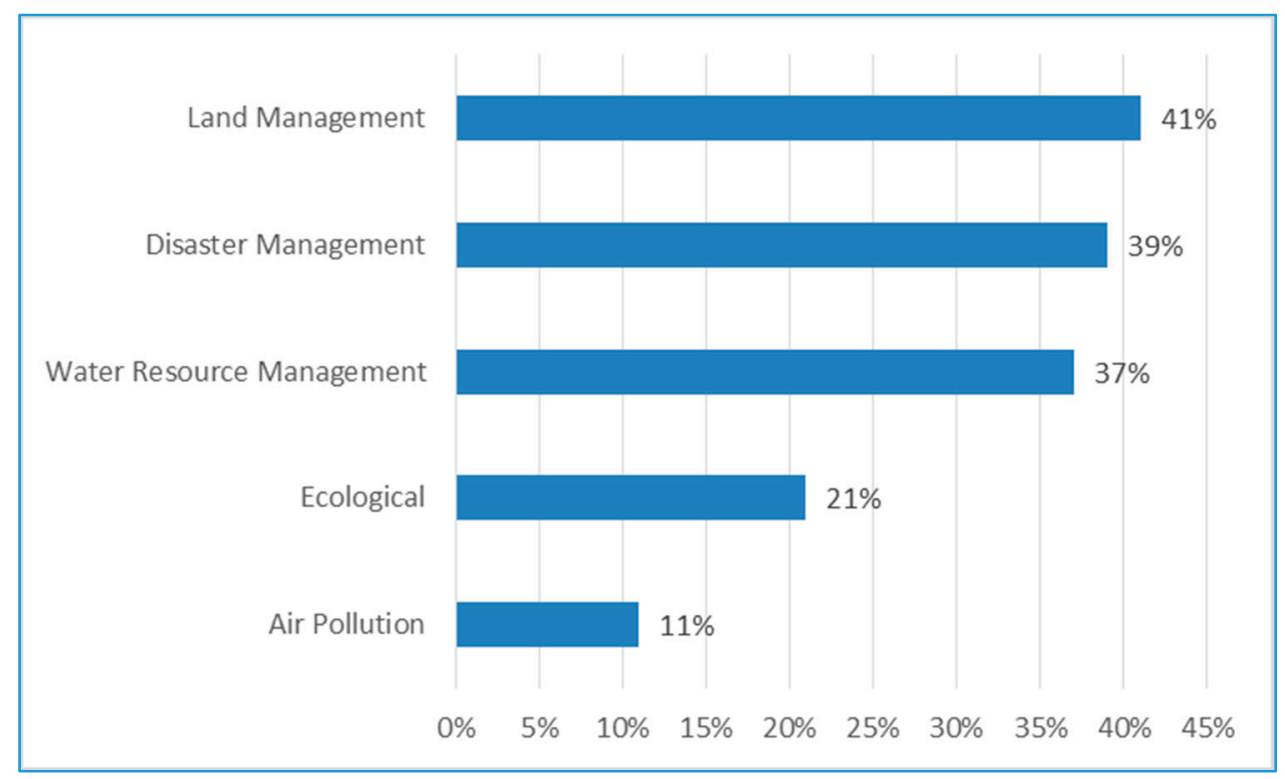

Figure 7. The self-identified areas of work applications in remote sensing by the alumni of ARCSSTE-E who responded to the post-training survey conducted in $2019(\mathrm{~N}=38)$.

The impact of the PGD programme on the work and career of the alumni is further expatiated by the following quotations from the alumni survey: "I am currently working with the Forestry Commission of Ghana as a GIS/Mapping officer. I run image classification to produce landuse/landcover maps, and landuse/landcover change maps to assess the forest cover in the country. I also developed a geo-database for the forest reserves and other natural resources. The skills and knowledge that I gained during my postgraduate studies at ARCSSTE-E have helped me in performing these tasks". Another alumnus stated that he applies "the knowledge of remote sensing using Unmanned Aerial Vehicles (UAVs) to carry out mapping, real-time surveillance in military operations, and I also apply GIS techniques in updating topographical maps using satellite imageries or drone data (Orthophoto)". Furthermore, in the educational sector, one alumnus indicated that he "once got a job as a geography teacher in an international secondary school, only to realise that remote sensing had been included in the curriculum. I was employed because of my RS/GIS certificate acquired at ARCSSTE-E, as this topic is alien to most geography teachers".

On the use of remote sensing data, $69 \%$ of the participants indicated the integration of remote sensing data in their operational environment. One alumnus specified the use of satellite data to establish electrification routes. Other uses include all forms of raster and vector data for natural resource management, cadastral mapping and urban space administration, hazard and environmental management, and climate change and modeling. The outcome of the "post-training survey" indicated that $100 \%$ of the alumni rated the training program of ARCSSTE-E high enough to be recommended to friends and colleagues.

\section{Best Practices}

Educational institutions in Africa often face challenges that hamper their ability to deliver on their mandates. ARCSSTE-E faces similar challenges, but it has devised innovative ways to tackle some of these challenges. ARCSSTE-E has learned a number of lessons since the commencement of its PGD programme. Some of these best practices, as gleaned from the feedback from participants, are highlighted in this section.

(i) Selection of Participants: At the inception of the programme, selection was based on nomination from an identified government agency in the country and endorsement of application by the government ministry in charge of foreign affairs. This led to the selection of students with poor academic performance 
and/or students without the stamina to withstand rigorous postgraduate education. In the recent past, applicants have applied directly to ARCSSTE-E and they were selected based on merit. However, they still need endorsement from the relevant Ministry in charge of Space Science and Technology in their home country. During the course of the programme, selected participants are taken on an official visit to their respective embassies in Nigeria.

(ii) Women's Participation: ARCSSTE-E strives to encourage the participation of women in the PGD programme by collaborating with local, national and international organisations. So far, of the 474 alumni, 66 are female (Figure 2). A total of $85 \%$ of these women opted for RS/GIS, while very few have participated in the other course options. The present 2019 cohort has 19 female participants, which represent over $40 \%$ of the PGD students that are enrolled for RS/GIS. This is the highest number of female participants that ARCSSTE-E has ever recorded since the inception of the PGD programme in 2001. The reason for this upsurge is due to the collaboration between ARCSSTE-E and the Nigerian National Space Research and Development Agency (NASRDA). These female participants are scientific officers, which were recruited by NASRDA, to promote the implementation of the Sustainable Developmental Goals of the United Nations (UN-SDG 5) on gender inequality in the space industry in Nigeria. These fresh university graduates were required to participate in the training programme of ARCSSTE-E, and achieve the PGD certificate before they could join the work force in the Space Applications Division of the Nigerian Space Agency since remote sensing and GIS are not offered in an undergraduate course in many Nigerian universities.

(iii) Seasoned African Instructors: It has been observed that a major problem confronting education in applied remote sensing in Africa is the dearth of well-trained African teachers [17]. Feedback from students indicated that the instructor played a key role in influencing the learning experience of the students. The teaching style and the quality of the instructor were rated as very important factors. The subject expertise of the teacher, the ability to link the different parts of the course in a logical flow, and the ability to effectively communicate knowledge by presenting what is generally conceived as difficult scientific concepts in simplified and readily comprehensible format, enhanced the learning experience of the students.

(iv) Innovative Instructional Methodology to Promote Learning: There are many challenges that are associated with education and training in applied remote sensing in Africa. A major problem is the inability of students to "see" the phenomena being taught. This often results in a failure to understand fundamental principles and an inability to relate the training to real-life problems [17]. In teaching the Fundamentals of Remote Sensing and GIS, ARCSSTE-E employs a training methodology that includes the use of instructional videos, digital animations, and models to help students to "see" the phenomena being taught. Mapping activities on the university campus with a hand-held Global Positioning System (GPS) and Google Earth are also used to establish the links between remote sensing and Geographic Information Systems (RS/GIS) concepts. Although the exercise of mapping the location of sites on a university campus appears to be a straightforward activity, when combined with Google Earth activities, it helps users to learn the basic skills of data collection, management, integration, and visualization [18]. These basic skills are important for users to have mastered prior to moving on to more complex geospatial activities.

(v) Regular Review of Course Content: ARCSSTE-E conducts a periodic survey of its alumni to enquire about their individual and institutional needs. ARCSSTE-E also keeps tab on global trends, so as to review its courses and prepare its participants to be part of the future workforce. For example, ARCSSTE-E is developing an online course, titled 'Spatial Data Analytics'. The course draws on the 'big data' paradigm.

(vi) Funding: Funding is one of the major challenges facing educational institutions. With regards to all of the Regional Centres, including ARCSSTE-E, the Member States are supposed to make statutory contributions to the operation of the Centres; however this has not always been so. In ARCSSTE-E, Nigeria bears all the burden of running the Centre, including staff salaries, utility bills and subsistence allowances for international students. The UNOOSA caters for only the travel cost of the international 
students. Over the years, the required financing from the host country Nigeria through its National Space Research and Development Agency (NASRDA) and from UNOOSA is most often inadequate. Rather than rely on these bodies, ARCSSTE-E devised an innovative funding mechanism, which included tuition fees from private-funded students, organisation of workshops, and research grants.

(vii) Management: As mentioned earlier in this paper, host countries of regional educational institutions often bear a large portion of the burden of management and funding. The UN Regional Centres have Governing Boards (GB), which have the responsibility of giving strategic oversight to the management team. For ARCSSTE-E, the participation of Member States in GB meetings has been poor. Up until 2012, the cost of bringing GB members to Nigeria was borne by the host country (Nigeria), with dwindling funds being accessible to the Centre. However, it has been unable to continue with this sponsorship. Therefore, ARCSSTE-E is making efforts to rotate the meeting venues of the GB among the Member States, so that they all have a sense of belonging and responsibility. When funds are available, ARCSSTE-E also invites experts from Member States to teach in the PGD programme.

\section{The Future Plans of ARCSSTE-E}

Through its educational and training programmes, ARCSSTE-E is striving to meet the capacity needs in remote sensing in the African region. A number of initiatives are under development consequent to previous and current surveys, including:

(i) Dearth of equipment for practical session: Hands-on and practical sessions are necessary for a complete academic experience. ARCSSTE-E is mindful of the need for increased hands-on sessions. For example, students in satellite communications do not have experience in setting up VSATs or a satellite communication system. ARCSSTE-E has been making efforts to procure modern equipment for teaching and learning to enrich the learning experience of the participants.

(ii) Accreditation: Though ARCSSTE-E is located within a university campus, the PGD programme of the Centre is not yet accredited by any university other than the UN affiliation, which has given it some global acceptability. This has been a challenge for alumni whose quest for further education has been turned down, because their certificates cannot be converted into the local system. However, this does not affect the standard of the programme (as the curricula is developed by the UNOOSA) or the viability of the diploma certificate (as it is endorsed by both ARCSSTE-E and UNOOSA). Nevertheless, ARCSSTE-E is making efforts to get its PGD programme accredited by the Obafemi Awolowo University (OAU), so that the diploma certificates can be easily converted into the university system of any country. The Masters certificate is already accredited by the Federal University of Technology, Akure (FUTA), Nigeria.

(iii) One-year home research project: While ARCSSTE-E has not implemented this, alumni have indicated that carrying out a one-year research project at home would be beneficial to their knowledge/career development and for their home countries. Carrying out a project in their home country would be an effective means of solidifying the knowledge gained while studying at ARCSSTE-E, as well as allowing for its application to problems in their home country. The participants are familiar with the challenges and conditions in their home countries; hence, they would be useful there.

(iv) Online programmes: As education and training becomes increasingly democratised and digitized, institutions need to consider the strategies for online- and distance-education. While there are a couple of popular free online courses, these are not meeting the particular needs of African countries. Online courses would also benefit interested participants who cannot leave their current work or family. In the future, ARCSSTE-E intends to run a free online course within a course option. The course could be taken at any convenient time within a stipulated period. The participants who completed the course would then be assessed while using online tools. Those that pass a minimum requirement in the online course would be invited to submit applications for a course option of their choice.

(v) E-learning programmes: Many students are not able to travel to Nigeria to undertake the nine month PGD programme, because they are working and cannot get paid study leave, due to family 
commitments, or because they cannot afford the cost. With an e-learning programme, participants could participate in the programme over the Internet. With e-learning, teaching, learning and assessment is only done via the Internet. Participants have no face-to-face meetings with their instructors. Currently, the Centre is collaborating with the university's e-learning unit and the ICT department to host the space e-learning platform.

(vi) PhD programme: Alumni have indicated interest in furthering their studies up to the $\mathrm{PhD}$ level. As a result of this, and considering the fact that the Regional Centres in India and China have started conducting PhD programmes, ARCSSTE-E has begun preparation to offer PhD programmes.

(vii) Short courses: Alumni have indicated interest in short courses (less than three months) and executive courses. Plans are in the offing for courses in location-based services (LBS) and geospatial data analytics. Executive courses are planned for those who have attained management positions and that need requisite knowledge to manage space application projects.

(viii) On-site courses: Alumni have also indicated interest in courses that are specifically tailored to their institutions. These courses would be organised in the office premises of the host institution.

(ix) Regional data/knowledge hub: With its access to data from Sentinel and other satellites, ARCSSTE-E aims to be the hub data repository for Africa. ARCSSTE-E is also making efforts to create an online knowledge repository, where lecture presentations, videos, and course materials will be uploaded for current participants and alumni to access.

(x) Alumni relations: The strength of an educational institution is enhanced through alumni relations. Alumni can make referrals, participate in volunteer teaching, mentor current students, and make donations to the institution. Alumni relations provide a platform to inform alumni of developments in ARCSSTE-E and opportunities for them to be part of present or future developments. ARCSSTE-E intends to pay more attention to alumni relations, as it affords previous participants the chance to engage with one another as they progress in their careers. The Centre has organised two alumni conferences in the past. This provided the opportunity for the re-union of alumni, interaction, and exchange of knowledge and experiences. Alumni are often very appreciative of the education and skills that they obtained while in ARCSSTE-E. Surveys are undertaken from time to time to gauge the feelings and experiences of the alumni [10]. Some found jobs, some had a change in career, some got promoted, and some achieved admission for further studies. Alumni frequently request reference letters from ARCSSTE-E, either for further studies or to participate in an international event.

(xi) International Cooperation: ARCSSTE-E leverages international cooperation to achieve some of its goals and objectives. Several Memorandum of Understandings (MoUs) have been signed with institutions, including the UN Regional Centre for Space Science and Technology Education for the Asia-Pacific Region, located in China (for staff training and organisation of training workshops); Samara State Aerospace University, Russia (for small satellite development); and, the European Organisation for the Exploitation of Meteorological Satellites (EUMETSAT), for downloading of satellite images. ARCSSTE-E achieved a 'participating organisation status', with the Group on Earth Observation (GEO) as well as the International Committee on GNSS (ICG). Within the region, educational institutions need to collaborate in research and development, as well as the sharing of teaching and learning facilities.

It our belief that ARCSSTE-E stands out as the connecting institution of Space Science and Technology for the region, especially in areas of capacity building and Space Outreach programmes. The Centre will seek collaboration with other international organisations that coordinate training programmes in applied remote sensing, such as the National Aeronautics and Space Administration's (NASA) Applied Remote-Sensing Training (ARSET) programme to support the effort of ARCSSTE-E in promoting applied remote sensing in Africa [19]. Such collaboration could help to develop the skills of current and future African instructors by sharing training resources.

(xii) Alliance of Regional Centres (ARC): ARCSSTE-E, in collaboration with other Regional Centres, has formed the Alliance of Regional Centres (ARC), which is affiliated to the United Nations. This is seen as a mechanism to share experiences, and to jointly plan and carry out activities to support the use of space to address development challenges. ARC will enhance existing capacity building partnerships 
and forge new ones. The organisational structure proposal is currently under consideration by UNOOSA for approval.

\section{Conclusions}

This paper discussed the education and training activities of ARCSSTE-E, and how ARCSSTE-E is preparing alumni for translating the acquired knowledge and skills into the workplace. We showed that the vision of the United Nations Office for Outer Space (UNOOSA) has been sustained and improved upon. While ARCSSTE-E faces similar challenges as other regional educational institutions, it has devised innovative means to implement its programmes, such as leveraging of online platforms, tuition fees from private-funded students, organisation of workshops, and research grants. The paper also reported on surveys that were conducted with current participants of the course, as well as alumni. Based on the analysis of their responses, there is clear evidence of the impact of the PGD programme on the careers and professions of the participants. An appreciable number of personnel that were trained by ARCSSTE-E are presently working in different countries in Africa and abroad. Finally, the paper discussed some future directions and recommendations that other institutions may adopt as best practice, such as increasing hands-on experience, accreditation by a university or professional institution, tailored training, and the leveraging of international cooperation.

Author Contributions: Conceptualisation, Ganiyu Agbaje, Omowumi Alabi and Etim Offiong; methodology, Omowumi Alabi and Etim Offiong; software, Omowumi Alabi and Etim Offiong; validation, Ganiyu Agbaje, Omowumi Alabi; formal analysis, Omowumi Alabi and Etim Offiong; writing-original draft preparation, Etim Offiong; writing-review and editing, Ganiyu Agbaje, Omowumi Alabi and Etim Offiong; supervision, Omowumi Alabi; project administration, Omowumi Alabi; funding acquisition, Ganiyu Agbaje and Omowumi Alabi.

Funding: This research received no external funding

Conflicts of Interest: The authors declare no conflict of interest.

\section{References}

1. United Nations General Assembly—Thirty-seventh Session. Available online: http://www.unoosa.org/pdf/ gares/ARES_37_90E.pdf (accessed on 5 May 2019).

2. UN Document A/AC.105/456, Annex II, Paragraph 4 (n), Report of the Scientific and Technical Subcommittee on the Work of its 27th Session, 12 March 1990; United Nations: New York, NY, USA, 1990.

3. UN Document A/RES/54/68, Paragraph 11(d), Third United Nations Conference on the Exploration and Peaceful Uses of Outer Space, 11 February 2000; United Nations: New York, NY, USA, 2000.

4. Kumar, A.B.; Aggarwal, S.P. Cross Border Education in Geoinformation Technologies and Applications in Asia and the Pacific-A CSSTEAP Experience. ISPRS Ann. Photogramm. Remote Sens. Spat. Inf. Sci. 2018, 5. [CrossRef]

5. United Nations. Capacity-Building in Space Science and Technology: Regional Centres for Space Science and Technology Education affiliated to the United Nations; United Nations Office for Outer Space Affairs: Vienna, Austria, 2008.

6. Haubold, H.J. Education curricula in space science and technology: the approach of the UN-affiliated regional centres. Space Policy 2003, 19, 221-223. [CrossRef]

7. Education Curricula. Available online: http://www.unoosa.org/oosa/en/ourwork/psa/regional-centres/study_ curricula.html (accessed on 21 June 2019).

8. Agbaje, G.I. Enhancing Space Education and Research in Microgravity among School Children in Africa: ARCSSTE-E UN-ZGIP Experience. In Proceedings of the Oral Presentation at the United Nations Expert Meeting on Human Space Technology, Vienna International Centre, Vienna, Austria, 4-6 December 2018; Available online: http://www.unoosa.org/documents/doc/psa/activities/2018/hsti_expert_meeting_vienna/ Presentations/Session2_11_Ganiy_Ishola_Agbaje.pdf (accessed on 6 May 2019).

9. Alabi, O.O.; Agbaje, G.I.; Akinyede, J.O. Strategy for Implementing the UN Zero-Gravity Instrument Project to Promote Space Science among School Children in Nigeria. In Proceedings of the Poster presentation at the American Geophysical Union (AGU) Fall Meeting, San Francisco, CA, USA, 14-18 December 2015; Available online: https://agu.confex.com/agu/fm15/meetingapp.cgi/Paper/76596 (accessed on 14 May 2019). 
10. Oladosu, O.; Offiong, E. Improving space knowledge in Africa: the ARCSSTE-E. Space Policy 2013, 29, 154-158. [CrossRef]

11. Agenda 2063. The Africa We Want. Available online: https://au.int/en/agenda2063/overview (accessed on 9 May 2019).

12. Goals \& Priority Areas of Agenda 2063. Available online: https://au.int/agenda2063/goals (accessed on 9 May 2019).

13. African Space Policy: Towards Social, Political and Economic Integration. Available online: https://au.int/sites/default/files/newsevents/workingdocuments/33178-wd-african_space_policy_-_ st20444_e_original.pdf (accessed on 9 May 2019).

14. African Space Strategy: Towards Social, Political and Economic Integration. Available online: https://au.int/sites/default/files/newsevents/workingdocuments/33178-wd-african_space_strategy_ -_st20445_e_original.pdf (accessed on 9 May 2019).

15. GMES and Africa-Background. Available online: https://au.int/en/GMESAfrica/background (accessed on 9 May 2019).

16. AUC awards Thirteen Consortia of Institutions to Implement the GMES and Africa Support Programme. Available online: http://gmes4africa.blogspot.com/2017/11/auc-awards-thirteen-consortia-of.html (accessed on 5 May 2019).

17. Haubold, H.J. Educational curricula of the UN-affiliated regional centres for space science and technology education. Space Policy 2003, 19, 67-69. [CrossRef]

18. Copper, G.; Alabi, O.; Awad, A.; Gens, R.; Prakash, A.; Witte, B. Litter retriever with a GPS receiver. In Exploration Tool Book; TERC: Cambridge, MA, USA, 2010; Available online: http://serc.carleton.edu/eet/litter_ gps/index.html (accessed on 3 May 2019).

19. Prados, A.I.; Carleton-Hug, A.; Gupta, P.; Mehta, A.; Blevins, B.; Schmidt, C.; Barbato, D.G.; McCullum, A.J.; Hook, E.; Podest, E.; et al. Impact of the ARSET Program on Use of Remote-Sensing Data. ISPRS Int. J. Geo-Inf. 2019, 8, 261. [CrossRef]

(C) 2019 by the authors. Licensee MDPI, Basel, Switzerland. This article is an open access article distributed under the terms and conditions of the Creative Commons Attribution (CC BY) license (http://creativecommons.org/licenses/by/4.0/). 